\title{
Inhibition of caspase-9 by oridonin, a diterpenoid isolated from Rabdosia rubescens, augments apoptosis in human laryngeal cancer cells
}

\author{
NING KANG ${ }^{1,3}$, SHI-JIE CAO ${ }^{4}$, YAN ZHOU ${ }^{4}, \mathrm{HAO} \mathrm{HE}^{3}$, SHIN-ICHI TASHIRO ${ }^{5}$, \\ SATOSHI ONODERA $^{6}$, FENG QIU $^{2}$ and TAKASHI IKEJIMA ${ }^{3}$ \\ ${ }^{1}$ School of Integrative Medicine, ${ }^{2}$ College of Traditional Chinese Medicine, \\ Tianjin University of Traditional Chinese Medicine, Tianjin 300193; \\ ${ }^{3}$ China-Japan Research Institute of Medical and Pharmaceutical Sciences, \\ ${ }^{4}$ Department of Natural Products Chemistry, Shenyang Pharmaceutical University, \\ Shenyang 110016, P.R. China; ${ }^{5}$ Institute for Clinical and Biomedical Sciences, Kyoto 603-8072; \\ ${ }^{6}$ Department of Clinical and Biomedical Science, Showa Pharmaceutical University, Tokyo 194-8543, Japan
}

Received July 16, 2015; Accepted September 11, 2015

DOI: 10.3892/ijo.2015.3186

\begin{abstract}
Rabdosia rubescens, a commonly used traditional Chinese medicine, has increasingly gained attention for its use as an antitumor herb. Oridonin, a bioactive diterpenoid isolated from Rabdosia rubescens, has been reported to induce apoptosis in human laryngeal cancer HEp-2 cells by our group. Here, we made unexpected observations that the caspase-9 inhibitor (C9i) enhanced apoptosis in response to selected stimuli, and HEp-2 cells which were made deficient in caspase-9 using siRNA exhibited no resistance to apoptotic signals and actually demonstrated increased apoptotic sensitivity to oridonin. The results were reversed by the transfection of an exogenous caspase- 9 expression vector. Caspase- 9 reduced sensitivity to apoptotic stimuli through reactive oxygen species (ROS)-suppressing and autophagy-promoting methods. ROS triggered the progression of apoptosis through
\end{abstract}

Correspondence to: Dr Takashi Ikejima, China-Japan Research Institute of Medical and Pharmaceutical Sciences, Shenyang Pharmaceutical University, 103 Wenhua Road, Shenyang 110016, P.R. China E-mail: ikejimat@vip.sina.com

Dr Feng Qiu, College of Traditional Chinese Medicine, Tianjin University of Traditional Chinese Medicine, 312 Anshanxi Road, Nankai District, Tianjin 300193, P.R. China

E-mail: fengqiu20070118@163.com

Abbreviations: ROS, reactive oxygen species; C9i, caspase-9 inhibitor; NAC, N-acetylcysteine; 3-MA, 3-methyladenine; LSCC, laryngeal squamous cell carcinoma; PI, propidium iodide; MDC, monodansylcadaverine; siRNA, small interfering RNA; CAT, catalase; FADD, Fas-associated protein with death domain; CAD, caspase-activated DNase; ICAD, inhibitor of caspase-activated DNase

Key words: oridonin, caspase-9, apoptosis, autophagy, reactive oxygen species activation of both the caspase-9-independent mitochondrial pathway and death receptor pathways, and the autophagy had an anti-apoptotic function in oridonin-treated HEp-2 cells. These collective results suggest that oridonin targets caspase- 9 to alter ROS production and autophagy situation to promote HEp-2 cell apoptosis. Therefore, oridonin has the potential to be developed as an anticancer agent, and the combination of oridonin with those agents leading to reduction of caspase- 9 expression in tumor cells could represent a novel approach to human laryngeal cancer treatment.

\section{Introduction}

Apoptosis (also known as type I programmed cell death) is a cellular suicide program critical for development and tissue homeostasis (1). Excess apoptosis is associated with degenerative disorders (2), while a failure of apoptosis contributes to oncogenesis (3). Anticancer agents can induce apoptosis in tumor cells that is mediated by the common cell death machinery. Central to this is a family of intracellular proteases, known as caspases. During apoptosis, they can act either as initiators (caspases-8 and -9) in response to apoptotic signals or as effectors (caspase-3, -6 and -7) that finally cleave a number of vital proteins and lead to the demise of the cells (1). ROS are generated from the mitochondria and other cellular sources, and can oxidize a wide range of cell constituents, including lipids, proteins and DNA, thus damaging cell structures and compromising function. When antioxidant mechanisms are overwhelmed by ROS and subsequent oxidative stress occurs, cell damage and cell death are induced (4). High levels of ROS induce cell death, which often involves apoptosis through caspase activation $(5,6)$.

As a mode of type II programmed cell death, autophagy is a series of biochemical steps through which eukaryotic cells commit suicide by degrading their own cytoplasm and organelles through a process in which these components are engulfed and then digested in double membrane-bound vacuoles called 
autophagosomes (7). However, autophagy has recently gained much attention for its paradoxical roles in cell survival and cell death, particularly in the pathogenesis as well as the treatment of cancer $(8,9)$. Whether autophagy enables cells to survive or enhances their death is context-driven, depending on the type of stimuli, nutrient availability, and apoptotic status (10).

Laryngeal squamous cell carcinoma (LSCC) is the most common squamous cell carcinoma of the head and neck, and there is a steady annual increase in new cases and deaths (11). Epidemiological studies have revealed that the incidence rates vary from country to country and in different population groups (12). LSCC accounts for $1-8.4 \%$ of all human cancers in China. However, only a minority of patients are eligible for radical treatment aimed at a cure. The availability of new cytotoxic drugs has led to steady improvements, but a paradigm shift is required to significantly affect the poor prognosis of most patients.

With a long history of cancer treatment, traditional Chinese medicine (TCM) is recognized as a valuable source for seeking bioactive anticancer compounds (13). Rabdosia rubescens (Hemsl.) Hara (Lamiaceae), also known as Dong Ling Cao in TCM, is commonly used in Chinese folk medicine to treat stomach aches, pharyngitis, sore throats, coughs and wrestling injuries. This herb has increasingly gained attention because of its use as an antitumor herb and because of the antitumor activities of its discovered bioactive constituents. The herb contains a variety of active components, including diterpenoids, flavonoids, phenolic acids, triterpenoids and volatile oils (14). Among these compounds, the diterpenoid compound oridonin (Fig. 1) was reported to possess inhibitory effects on a variety of cancer cell lines, such as leukemia, colorectal cancer, esophageal cancer, liver cancer, epidermoid carcinoma, lung cancer and uterine cervical cancer $(15,16)$. However, no reports has yet been found on its anticancer effects in human laryngeal cancer cells until our laboratory demonstrated that oridonin could induce apoptosis and G2-M phase arrest in human laryngeal squamous carcinoma HEp-2 cells (17).

During the course of characterizing the role of the mitochondrial pathway in oridonin-induced apoptosis in HEp-2 cells, we made an unexpected observation that a selective inhibitor of caspase-9 (C9i) could enhance (rather than retard) apoptosis in response to selected stimuli. Interestingly, our group also found that caspases did not mediate apoptosis, but protected L929 cells from oridonin-induced cell death (18). Moreover, Shah et al also found that a caspase-9 inhibitor could enhance stress-induced apoptosis in B-lineage cells (19). Driven by the above-mentioned interesting phenomena, we set out to delineate the signaling pathways and specifically the role of caspase-9 in oridonin-induced apoptosis in greater detail. Our data showed that caspase- 9 played an anti-apoptotic role in HEp-2 cells through inhibition of ROS generation. Further, we discovered that caspase- 9 promoted oridonin-induced autophagy, and in this context, autophagy was a protective mechanism against apoptosis.

\section{Materials and methods}

Cell culture and reagent treatment. Human laryngeal cancer HEp-2 cells were obtained from the American Type Cell Culture Collection and were cultured as previously described
(20). Oridonin was isolated from Rabdosia rubescens and was identified by comparing its physical and spectroscopic $\left({ }^{1} \mathrm{H} \mathrm{NMR},{ }^{13} \mathrm{C} \mathrm{NMR}\right)$ data with those reported in the literature (21). The purity was measured by HPLC (column: 4.6x150 mm, Inertsil ODS-SP, $5 \mu \mathrm{m}$; solvent phase: methanol/ $\mathrm{H}_{2} \mathrm{O}, 55: 45$ ) and determined to be $99.6 \%$. Oridonin was dissolved in DMSO to obtain a stock solution. The DMSO concentration was kept below $0.05 \%$ in all the cell cultures so that it had no detectable effect on cell growth or cell death.

Growth inhibition assay. HEp-2 cells were incubated in 96-well tissue culture plates. After a 24-h incubation, the cells were treated with, or without, pan-caspase inhibitor (z-VADfmk), caspase-9, -8, -3, -1 inhibitors [Ac-LEHD-cmk (C9i), z-IETD-fmk, z-DEVD-fmk or Ac-YVAD-cmk], 3-MA or NAC (Sigma) at the given concentrations for $1 \mathrm{~h}$ and subsequently treated with oridonin for $24 \mathrm{~h}$. The cytotoxic effect was measured by MTT assay as described elsewhere (20).

Observation of morphological changes. HEp-2 cells were seeded into 6-well culture plates. After a 24-h incubation, the cells were treated with, or without, $\mathrm{C} 9 \mathrm{i}$ or NAC at the given concentrations for $1 \mathrm{~h}$ and subsequently incubated with oridonin for $24 \mathrm{~h}$. The cellular morphology was observed using a phase contrast microscope (Leica, Nussloch, Germany).

Transmission electron microscopy. HEp-2 cells were treated with $36 \mu \mathrm{M}$ oridonin for the indicated time periods. The collected cells were fixed with PBS containing 3\% glutaraldehyde, and postfixed with PBS containing $1 \% \mathrm{OsO}_{4}$. The samples were dehydrated in graded alcohol solutions, then embedded and sectioned. Ultrathin sections were stained with uranyl acetate and lead citrate, and examined using a JEM-1200 transmission electron microscope (Jeol, Tokyo, Japan) (22).

Flow cytometric analysis of cell apoptosis. After chemical treatment, $1 \times 10^{6}$ cells were harvested. The collected cells were fixed in $70 \%$ ethanol, stained for DNA content with propidium iodide (PI), and measured by flow cytometry (BectonDickinson, Franklin Lakes, NJ, USA) as previously described (20). The sub-G1 DNA content was used as an indicator of apoptosis (23).

Measurement of intracellular ROS generation. After treatment with $36 \mu \mathrm{M}$ oridonin for the indicated time periods, the cells were incubated with $10 \mathrm{mM} \mathrm{DCF-DA} \mathrm{(Sigma)} \mathrm{at} 37^{\circ} \mathrm{C}$ for $30 \mathrm{~min}$. The intracellular ROS caused oxidation of DCF-DA to the fluorescent compound DCF. Then, the cells were harvested and the pellets were suspended in $1 \mathrm{ml}$ PBS. Samples were analyzed at an excitation wavelength of $480 \mathrm{~nm}$ and an emission wavelength of $525 \mathrm{~nm}$ by FACScan flow cytometry (18).

Determination of mitochondrial membrane potential. The mitochondrial membrane potential was measured using the fluorescent dye rhodamine-123 (Sigma) by flow cytometry as previously described (20).

Measurement of autophagy. After incubation with $36 \mu \mathrm{M}$ oridonin for the fixed times, cells were cultured with $0.05 \mathrm{mM}$ 


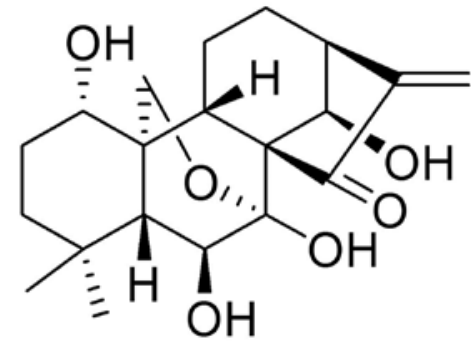

Figure 1. Chemical structure of oridonin.

monodansylcadaverine (MDC) at $37^{\circ} \mathrm{C}$ for $60 \mathrm{~min}$. The cellular fluorescent changes were observed under a fluorescence microscope (Olympus). The fluorescence intensity of cells was analyzed by FACScan flow cytometry (24).

Assay for caspase-9 activity. A caspase-9 fluorimetric assay kit from Chemicon International (Temecula, CA, USA) was used according to the manufacturer's instructions. Briefly, cell lysates were incubated with peptide substrate, LEHD-pNA (Ac-Leu-Glu-His-Asp-pNA), in assay buffer [100 mM NaCl, $50 \mathrm{mM}$ HEPES, $10 \mathrm{mM}$ DTT, $1 \mathrm{mM}$ EDTA, $10 \%$ glycerol, $0.1 \%$ CHAPS ( $\mathrm{pH} 7.4$ )] for $2 \mathrm{~h}$ at $37^{\circ} \mathrm{C}$. The release of p-nitroaniline was monitored at $405 \mathrm{~nm}$. Caspase- 9 activity in cell lysates was expressed as the $\mathrm{x}$-fold increase from baseline controls.

RNA interference. HEp-2 cells were transfected with caspase-9 small interfering RNA (siRNA) and control siRNA (Shanghai GenePharma, China) by Lipofectamine 2000 (Invitrogen) according to the manufacturer's instructions. The sequences of the sense strands of the RNAs used in this study were as follows. Control siRNA: UUC UCC GAA CGU GUC ACG. Caspase-9 siRNA-1: CGG UGA AAG GGA UUU AUA ATT. Caspase-9 siRNA-2: CCA AAG UUG UCG AAG CCA ATT CGU UGA. Caspase-9 siRNA-3: GUG ACA UCU UUG UGU CCU ATT.

Transient transfection. HEp-2 cells at $70 \%$ confluence were transfected with control pcDNA3.1-3FLAG and pcDNA3.1-hCASP9-3FLAG plasmid (Shanghai GeneChem, China). Transfection of cells was performed by using Lipofectamine 2000 reagent according to the manufacturer's protocol. The effectiveness of transfection was detected by western blot analysis.

Preparation of mitochondrial and cytosolic extracts. HEp-2 cells were collected and then washed twice with ice-cold PBS. The cell pellets were resuspended in ice-cold homogenizing buffer (250 mM sucrose, $20 \mathrm{mM}$ HEPES, $10 \mathrm{mM} \mathrm{KCl,} 1.5 \mathrm{mM}$ $\mathrm{MgCl}_{2}, 1 \mathrm{mM}$ EDTA, $1 \mathrm{mM}$ EGTA, $1 \mathrm{mM}$ dithiothreitol, $0.1 \mathrm{mM}$ phenylmethanesulfonyl fluoride, $10 \mu \mathrm{g} / \mathrm{ml}$ pepstatin and $10 \mu \mathrm{g} / \mathrm{ml}$ leupeptin). The cells were then homogenized and centrifuged at $14,000 \mathrm{~g}$ at $4^{\circ} \mathrm{C}$ for $60 \mathrm{~min}$. The supernatant was used as the cytosol fraction and the pellet was resuspended in lysis buffer as the membrane fraction (25).

Western blot analysis. Western blot analysis was performed as previously described (20) using corresponding antibodies against Beclin 1, LC3, Bax, Bcl-2, AIF, cytochrome $c$, ICAD, FADD, caspase-9, -8, -3, Hsp90, $\beta$-actin (Santa Cruz). Representative blots from three independent experiments are shown.

Statistical analysis of the data. All the presented data and results were confirmed in at least three independent experiments. The data are expressed as means \pm SD. Statistical comparisons were made by Student's t-test and $\mathrm{P}<0.05$ was considered statistically significant.

\section{Results}

The apoptotic effects of oridonin in HEp-2 cells are enhanced by an irreversible inhibitor of caspase-9. Some of our preliminary studies have indicated that oridonin is able to inhibit the proliferation of human laryngeal squamous carcinoma HEp-2 cells, and the cell death is shown to be typical of apoptosis $(17,20)$. Since it is well known that caspase family members play a pivotal role in the cell apoptosis process, the effect of caspase inhibitors on oridonin-induced HEp-2 cell death was examined. Unexpectedly, the C9i enhanced cell death due to oridonin stimuli, while z-DEVD-fmk, z-IETD-fmk and Z-VAD-fmk blocked the cytotoxity of the response to oridonin (Fig. 2A).

Further, we investigated whether inhibition of caspase-9 affected drug sensitivity. As shown in Fig. 2B, pre-treatment of HEp-2 cells with 5-20 $\mu \mathrm{M}$ C9i markedly enhanced the inhibitory ratio in a dose-dependent manner after treatment with oridonin. In addition, we examined cellular morphological changes by phase contrast microscopy. At $24 \mathrm{~h}$, some of oridonin-treated HEp-2 cells became round, with shrunken nuclei and membrane blebbing, while untreated cells did not show these apoptotic characteristics (Fig. 2C). Whereas, the $\mathrm{C} 9 \mathrm{i}$-pre-treated group showed more marked apoptotic changes in a dose-dependent manner (Fig. 2C). Quantification of apoptotic cells by flow cytometric analysis also showed that combined treatment with oridonin and C9i caused more significant apoptosis, and the apoptotic ratio was observed to be significantly increased from $15.08 \%$ in oridonin alonetreated cells to $23.59,31.54$ and $37.26 \%$ in 5,10 and $20 \mu \mathrm{M} \mathrm{C} 9 \mathrm{i}$ pre-treated cells, respectively (Fig. 2D).

Oridonin-induced increase in ROS generation is enhanced by inhibiting caspase-9. Dysregulation of cellular redox status can be a potent mechanism of cell death (26). Therefore, we tested the possibility that oridonin, with or without C9i, induces apoptosis through ROS accumulation. Compared with the control group, ROS generation was significantly increased after exposure to oridonin for $24 \mathrm{~h}$. C9i effectively increased oridonin-induced intracellular ROS generation (Fig. 3A and B). As expected, the use of NAC, a well known ROS scavenger (27), almost completely blocked ROS generation induced by oridonin alone or in combination with C9i (Fig. 3A and B). Whereas, NAC not only completely prevented HEp-2 cell apoptosis induced by oridonin alone, but also reversed the cell apoptosis induced by combined treatment with oridonin and C9i (Fig. 2C and D). Collectively, these results demonstrated that caspase-9 inhibition amplified oridonin-induced oxidative stress, which leads to enhanced apoptosis. 

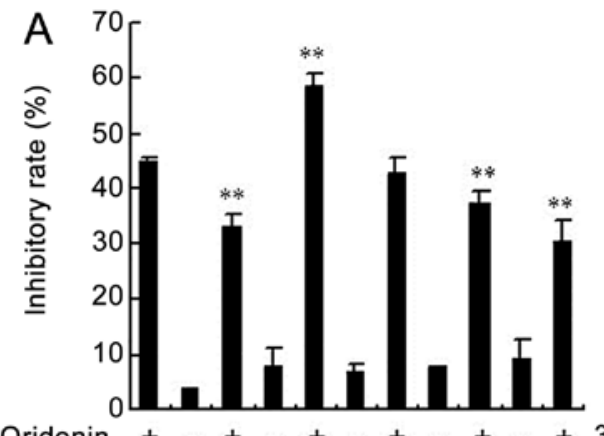

B

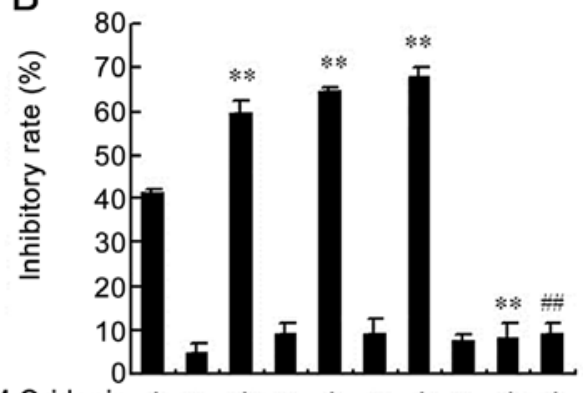

$36 \mu \mathrm{M}$ Oridonin

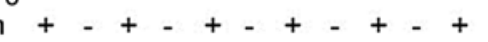

$36 \mu \mathrm{M}$ Oridonin

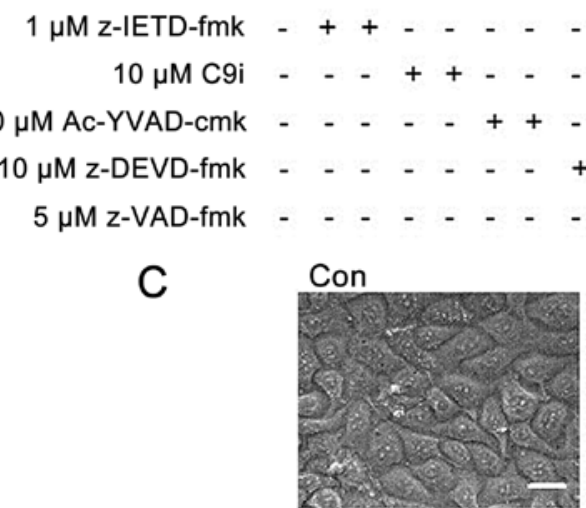

C9i $(5 \mu \mathrm{M})$

C9i $(10 \mu \mathrm{M})$

C9i $(20 \mu \mathrm{M})$

$2.5 \mathrm{mM} \mathrm{NAC}$
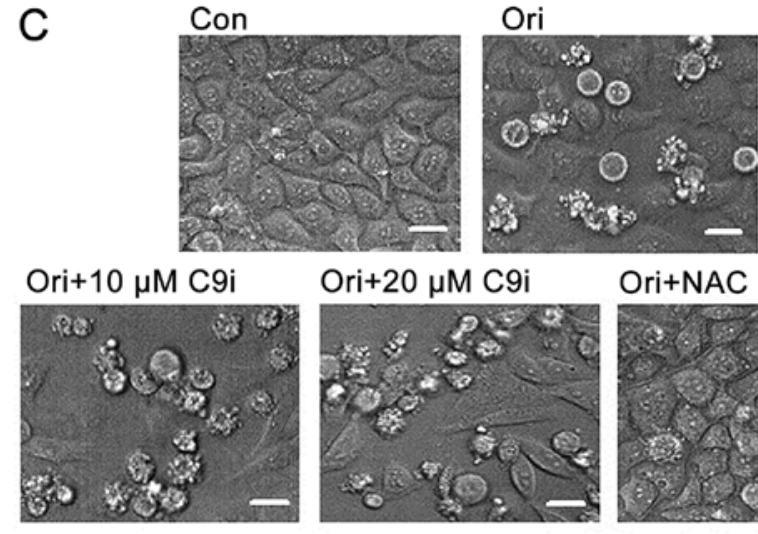

Ori+5 $\mu \mathrm{M} \mathrm{C9i}$

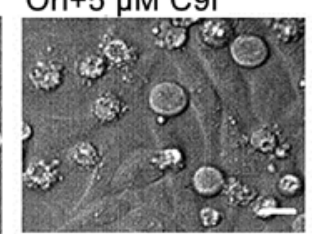

Ori+NAC

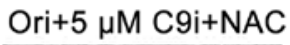

D

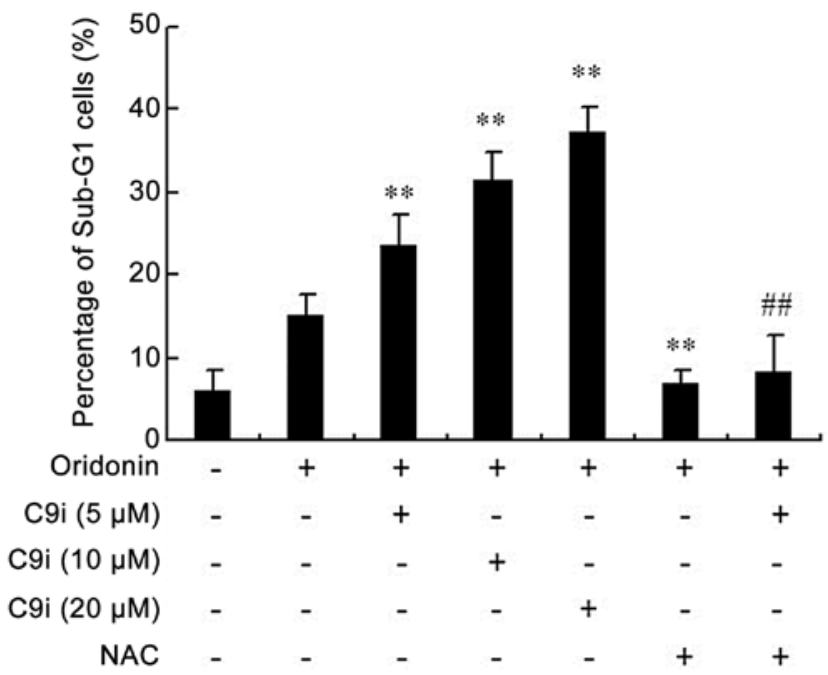

Figure 2. The growth-inhibitory ratio and apoptotic ratio were enhanced by C9i but inhibited by NAC in oridonin-treated HEp-2 cells. (A) The cells were treated with oridonin for $24 \mathrm{~h}$, in the presence or absence of caspase- $9,-8,-3$ and -1 inhibitors or pan-caspase inhibitor, and the inhibitory ratio was measured by MTT assay, $n=3$, mean \pm SD. After the cells were incubated with oridonin in the absence or presence of C9i or NAC for $24 \mathrm{~h}$, the inhibitory ratio was measured by MTT assay, $\mathrm{n}=3$, mean $\pm \mathrm{SD}(\mathrm{B})$, and the morphological changes were examined by phase contrast microscopy; scale bar, $10 \mu \mathrm{m}(\mathrm{C})$. The flow cytometric quantification of apoptotic cells (sub-G1 fraction) is shown (D). ${ }^{* *} \mathrm{P}<0.01$ vs oridonin alone-treated group; ${ }^{\# \#} \mathrm{P}<0.01$ vs oridonin co-treated with $5 \mu \mathrm{M}$ C9i group.

Oridonin triggers a marked loss of $\Delta \Psi m$ and caspase-9 inhibition produces a progressive loss of $\Delta \Psi \mathrm{m}$. It has been reported that ROS generation can lead to mitochondrial damage and membrane depolarization (28). Therefore, we investigated whether ROS targeted the mitochondria and thereby decreased the $\Delta \Psi m$ in our model. As shown in
Fig. 3C and D, exposure of HEp-2 cells to oridonin for $24 \mathrm{~h}$ caused a marked loss of $\Delta \Psi m$ compared with the control group and C9i pre-treatment produced a progressive loss of $\Delta \Psi m$. Notably, pre-treatment with NAC reversed the disruption in $\Delta \Psi m$ induced by oridonin alone or in combination with C9i (Fig. 3C and D). These results suggested that the 
A
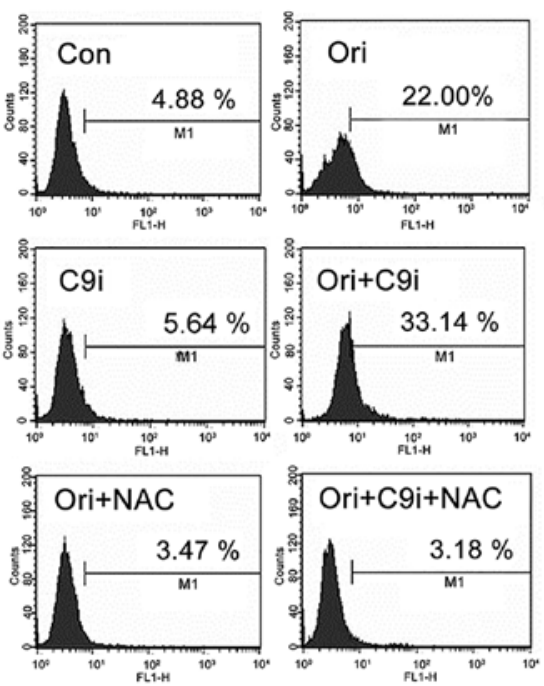

C
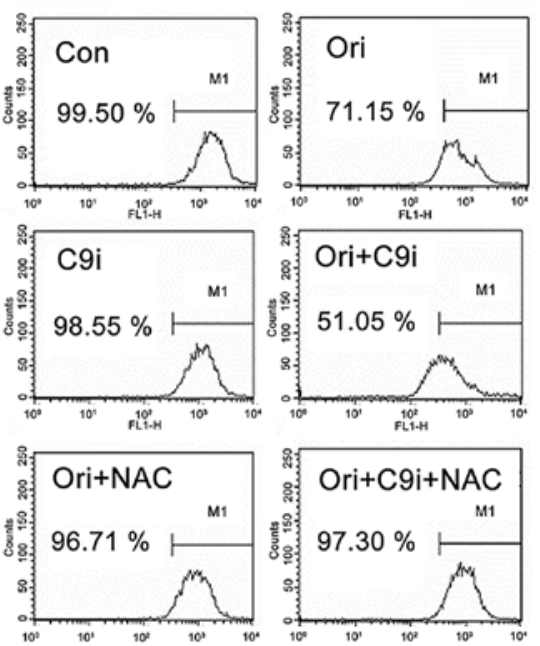

E

Oridonin

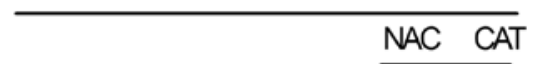

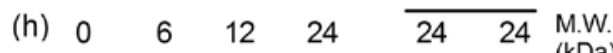

$\mathrm{Bax} \square-23$

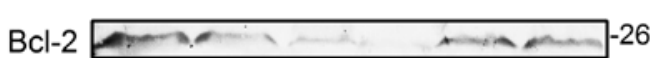

AIF $\square-57$
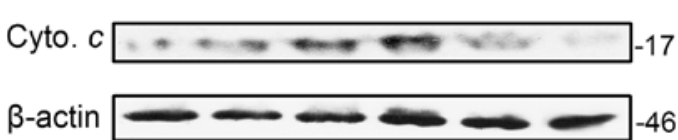

B

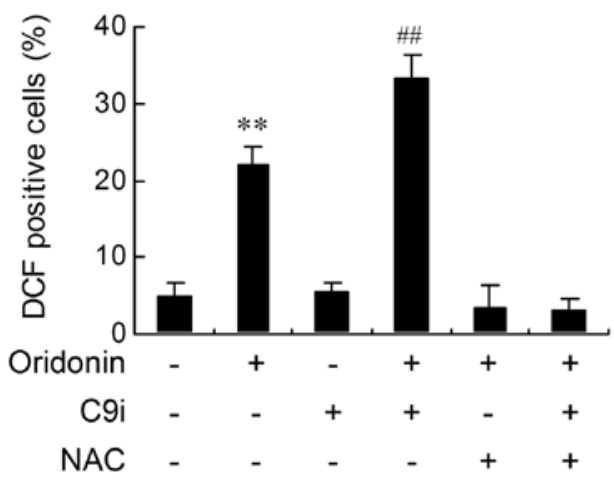

D

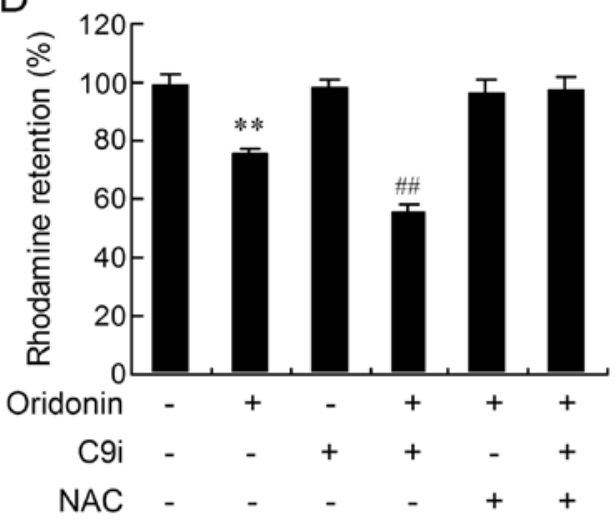

F

Oridonin

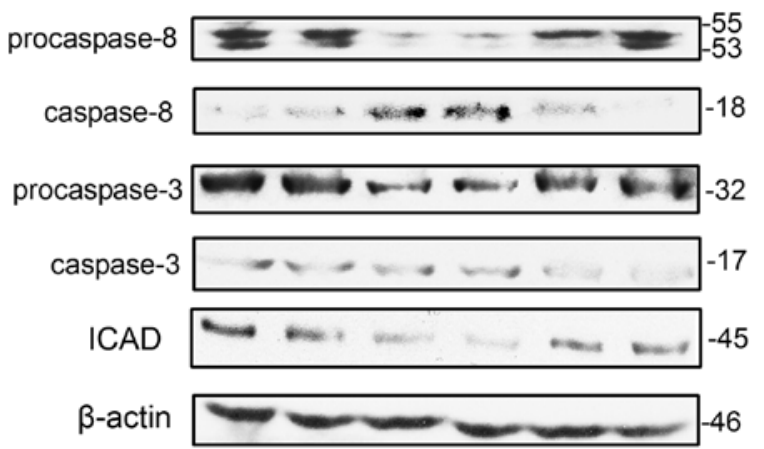

Figure 3. C9i amplifies the ROS production induced by oridonin, and the ROS subsequently triggers the progression of apoptosis in HEp-2 cells. The cells were cultured in the presence of $36 \mu \mathrm{M}$ oridonin for 0 or $24 \mathrm{~h}$ or co-incubated with $5 \mu \mathrm{M}$ C9i or $2.5 \mathrm{mM}$ NAC for $24 \mathrm{~h}$. Then, ROS generation (A) and the changes in $\Delta \Psi m(\mathrm{C})$ were measured by flow cytometry. The corresponding linear diagrams of the FACScan histograms are shown in (B) and (D) respectively. The values are mean \pm standard errors ( $\mathrm{n}=3$ of individual experiments). The cells were treated with oridonin in the absence or presence of $2.5 \mathrm{mM} N \mathrm{NAC}$ or $500 \mathrm{U} / \mathrm{ml}$ CAT for the indicated time periods, then Bax, Bcl-2, cytochrome $c$, AIF (E) and FADD, caspase-8, -3 , ICAD (F) protein expression was detected by western blot analysis. The results shown here are representative of at least three independent experiments. ${ }^{* *} \mathrm{P}<0.01 \mathrm{vs}$ control group. ${ }^{\# \#} \mathrm{P}<0.01 \mathrm{vs}$ oridonin alone-treated group.

oridonin, with or without $\mathrm{C} 9 \mathrm{i}$, was capable of inducing mitochondrial dysfunction and that the loss of $\Delta \Psi m$ might be affected directly by ROS generation.
Oridonin-induced Bax activation, Bcl-2 degradation, cytochrome $c$ and AIF elevation are markedly blocked by NAC and CAT treatment. To determine the possible causes and 
A
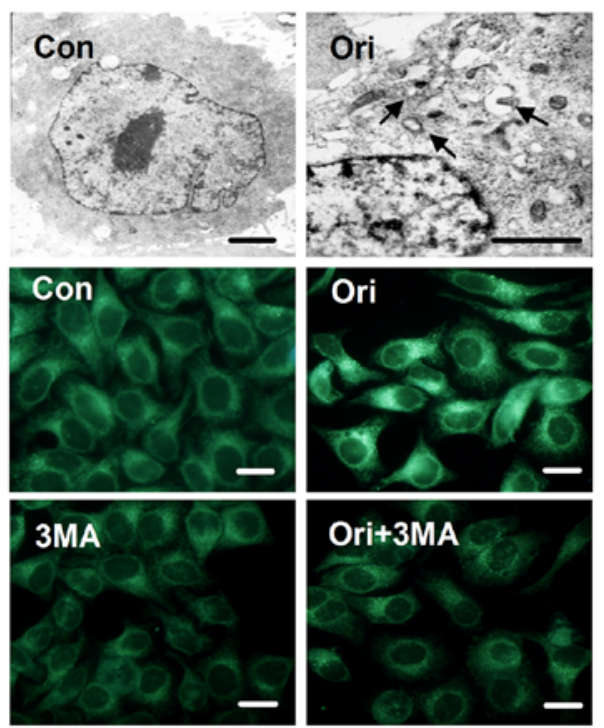

C
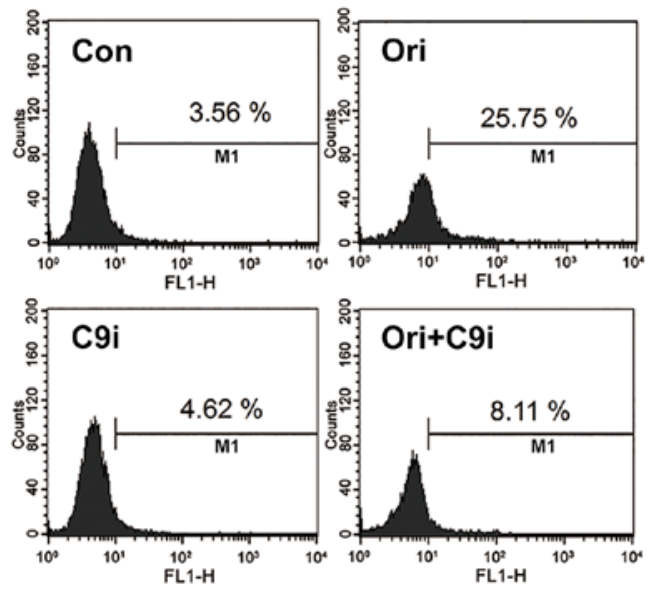

E

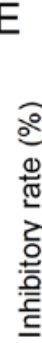

Oridonin

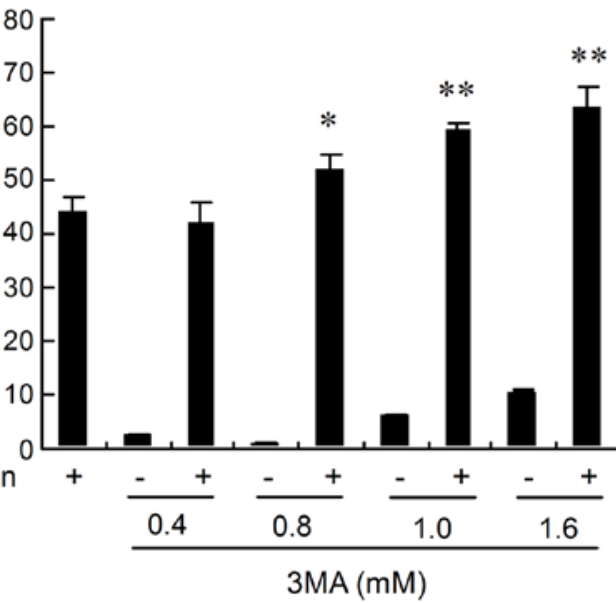

B

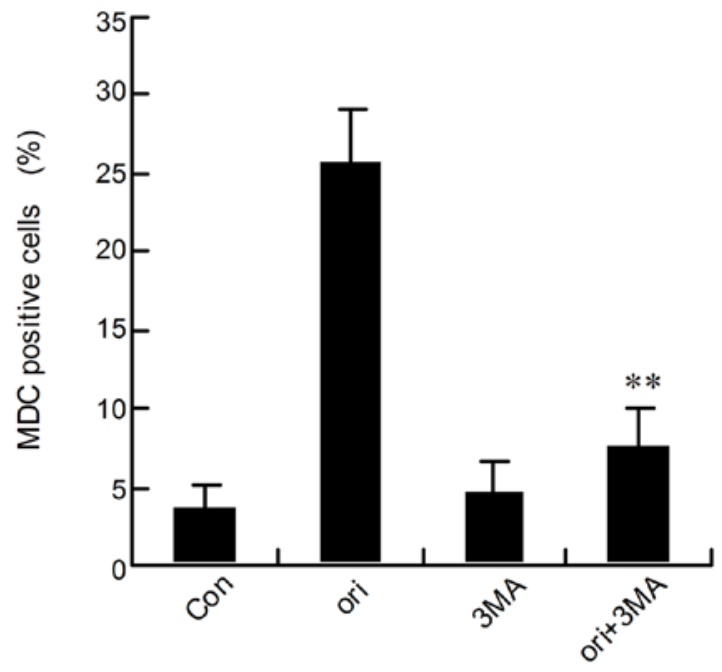

D

Oridonin

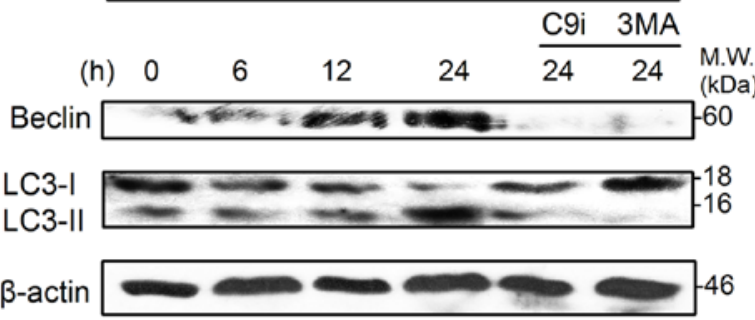

$\mathrm{F}$

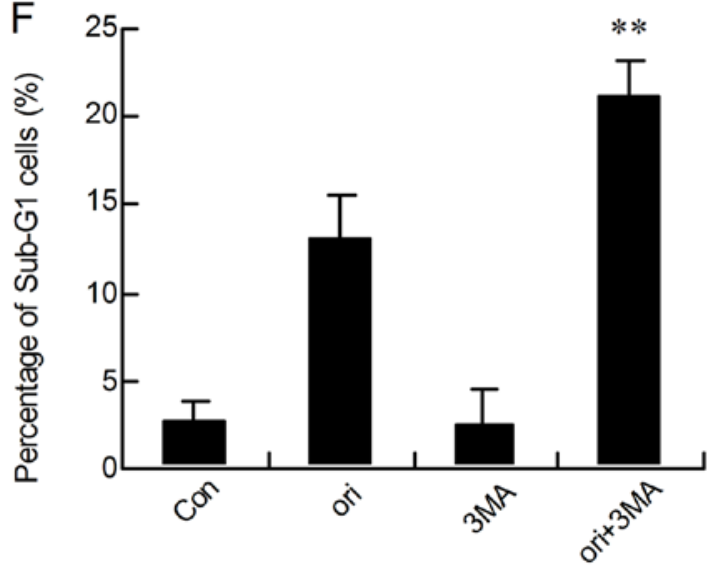

Figure 4. Caspase-9 facilitates oridonin-induced autophagy, and inhibition of autophagy upregulates apoptosis. (A) The cells were incubated with oridonin for 0 or $24 \mathrm{~h}$, or co-incubated with 3-MA for $24 \mathrm{~h}$. Then, the cellular morphological changes were observed by transmission electron microscopy (arrow indicates autophagic vacuoles; scale bar, $1 \mu \mathrm{m}$ ) or by fluorescence microscopy with MDC staining (scale bar, $10 \mu \mathrm{m}$ ). The cells were cultured in the presence of oridonin or co-incubated with $1 \mathrm{mM} 3-\mathrm{MA}$ (B) or $5 \mu \mathrm{M} \mathrm{C} 9 \mathrm{i}$ (C) for $24 \mathrm{~h}$. The corresponding column or flow cytometric histograms of autophagic level changes are represented. (D) The cells were treated with oridonin in the presence or absence of 3-MA or C9i for the indicated time periods, followed by western blot analysis for Beclin 1 and LC3 levels. The results shown here are representative of at least three independent experiments. (E) The cells were treated with oridonin for $24 \mathrm{~h}$, in the presence or absence of 0.4-1.6 mM 3-MA, and the inhibitory ratio was measured by MTT assay, $\mathrm{n}=3$, mean \pm SD. (F) The cells were treated with oridonin for $24 \mathrm{~h}$ in the presence or absence of $1 \mathrm{mM} 3-\mathrm{MA}$. The sub-G1 fraction was analyzed by flow cytometry. ${ }^{*} \mathrm{P}<0.05$ or ${ }^{* * *} \mathrm{P}<0.01 \mathrm{vs}$ group treated with oridonin alone.

consequences of the $\Delta \Psi m$ decrease, we studied the presence of two proteins, pro-apoptotic protein Bax and anti-apoptotic protein $\mathrm{Bcl}-2$, which are involved in the regulation of mito- chondrial permeability and two other proteins, cytochrome $c$ and AIF, which are usually released from mitochondria during apoptosis. We found that oridonin treatment 
significantly increased and decreased levels of Bax and Bcl-2 proteins, respectively, in a time-dependent manner (Fig. 3E). The expression of cytochrome $c$ was markedly elevated. Simultaneously, a visible increase in AIF levels was also detectable after 12- and 24-h incubation (Fig. 3E). However, NAC and catalase (CAT, hydrogen peroxide decomposer) pre-treatment completely reversed the changes in Bax, Bcl-2, cytochrome $c$ and AIF (Fig. 3E).

Changes stimulated by oridonin in FADD, caspase-8, caspase-3 and ICAD expression are inhibited by NAC and $C A T$. To assess whether the Fas-mediated pathway was activated in oridonin-treated cells, the expressions of Fas-associated protein with death domain (FADD), caspase- 8 and -3 were determined by western blot analysis. The expression of FADD was markedly elevated and there was clear cleavage of procaspase- 8 after oridonin administration. A time-dependent cleavage of procaspase-3 was also observed in oridonin-treated cells (Fig. 3F). ICAD, an inhibitor of caspase-activated DNase (CAD), is a substrate for caspases such as caspase- 3 . When caspase- 3 is activated by apoptotic stimuli, ICAD is cleaved, resulting in the release of CAD which appears to cause DNA fragmentation in the nuclei (29). As shown in Fig. 3F, oridonin induced degradation of ICAD in HEp-2 cells in a time-dependent manner. Addition of NAC and CAT markedly inhibited the changes in FADD, caspase-8, -3 and ICAD (Fig. 3F).

Caspase-9 facilitates oridonin-induced autophagy. We first investigated the effect of oridonin on cell autophagy. The ultrastructural details displayed that the oridonin-treated cells possessed typical characteristics of autophagy. These characteristic changes included extensive cytoplasmic vacuolization, and some autophagic vacuoles contained degraded organelles (Fig. 4A). The formation of autophagic vacuoles was further assessed by MDC, a fluorescent dye specifically staining autophagosomes. As shown in Fig. 4A, control cells presented diffused staining, and oridonin treatment resulted in an extensive punctuate MDC staining pattern. Next, the levels of Beclin 1 and LC3, two important proteins involved in autophagy $(10,30)$, were examined by western blot analysis. As shown in Fig. 4D, the level of Beclin 1 and conversion from LC3-I to LC3-II both increased with time after oridonin administration. These findings apparently reveal that autophagy is induced as a response of HEp-2 cells to oridonin treatment.

To explore the involvement of caspase- 9 in the modulation of autophagy, the autophagic ratio was measured by flow cytometry. Compared with the oridonin treatment group, the autophagic ratio was significantly reduced by the combined use of oridonin and C9i (Fig. 4C). Accordingly, the treatment of C9i markedly suppressed Beclin 1 upregulation and the conversion from LC3-I to LC3-II (Fig. 4D), suggesting the autophagy-promoting effects of caspase- 9 .

Inhibition of autophagy upregulates apoptosis induced by oridonin in HEp-2 cells. To investigate the role of autophagy in oridonin-induced apoptosis in HEp-2 cells, 3-MA, a specific inhibitor of autophagy, was introduced. Treatment with 3-MA prior to the addition of oridonin induced a significant reduc-
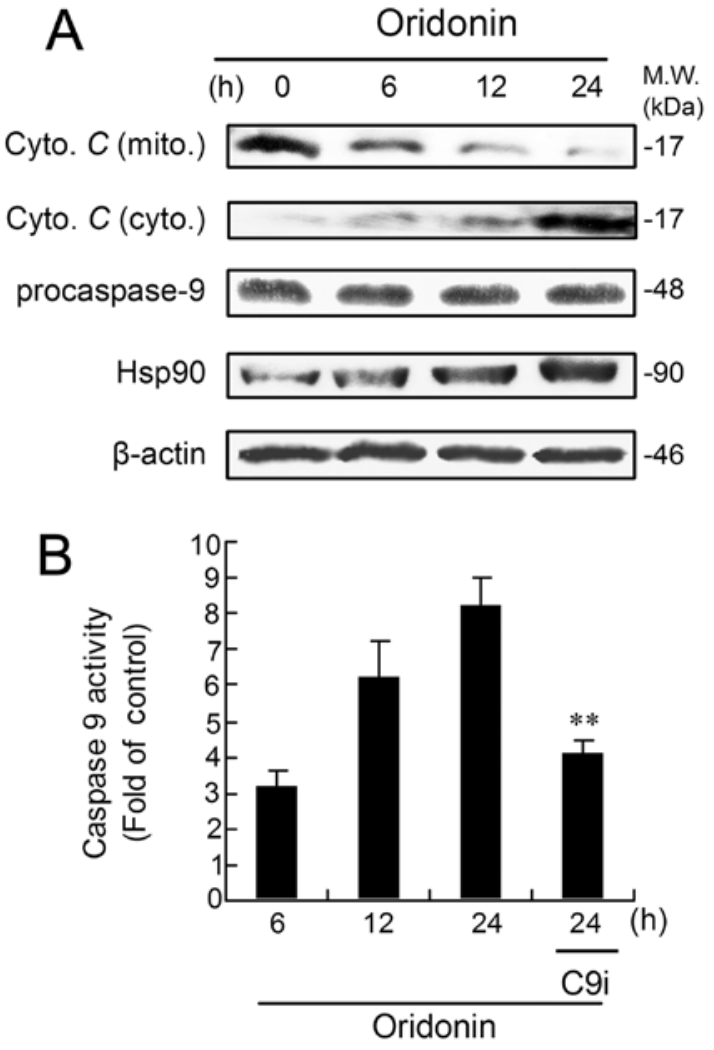

Figure 5. Time-course of activation of caspase-9 is not dependent on proteolytic cleavage. (A) The cells were treated with oridonin for the indicated time periods, followed by western blot analysis for detection of caspase-9, Hsp90 and cytochrome $c$ (both in the cytosol and the mitochondria) levels. The results shown here are representative of at least three independent experiments. (B) Equivalent cultures were prepared and the cells were collected to assess the enzymic activity of caspase- 9 as described in Materials and methods, $\mathrm{n}=3$, mean $\pm \mathrm{SD}$. ${ }^{* *} \mathrm{P}<0.01$ vs group treated with oridonin for $24 \mathrm{~h}$.

tion in the number of MDC-labeled fluorescent particles in the cells (Fig. 4A). Flow cytometric analysis also indicated that pre-treatment with 3-MA markedly reduced the autophagic ratio compared with the group treated with oridonin alone (Fig. 4B). Simultaneously, oridonin-induced Beclin 1 activation as well as the modification of LC3-I to LC3-II were markedly blocked when the cells were pre-treated with 3-MA (Fig. 4D). However, pre-treatment of HEp-2 cells with 0.4-1.6 mM of 3-MA dramatically increased the inhibitory rate of cell growth in a dose-dependent manner after oridonin treatment (Fig. 4E). Further, inhibition of autophagy increased the oridonin-induced sub-G1 cell proportion (an index of apoptosis) in HEp-2 cells (Fig. 4F). Collectively, these results suggested that 3-MA inhibited oridonin-mediated autophagy and it also sensitized the cells to the cytotoxic actions of oridonin with induction of apoptosis. In short, oridonininduced autophagy inhibits apoptosis in our model.

Evaluation of the expression pattern of critical apoptosome complex-related proteins. In the cytosol, cytochrome $c$ binds to Apaf-1, allowing recruitment of caspase-9 and formation of apoptosome, resulting in caspase- 9 activation and execution of cell death $(31,32)$. Here, the expression of critical apoptosome complex-related proteins was examined by means of western blot analysis. As shown in Fig. 5A, the level of cytochrome $c$ 

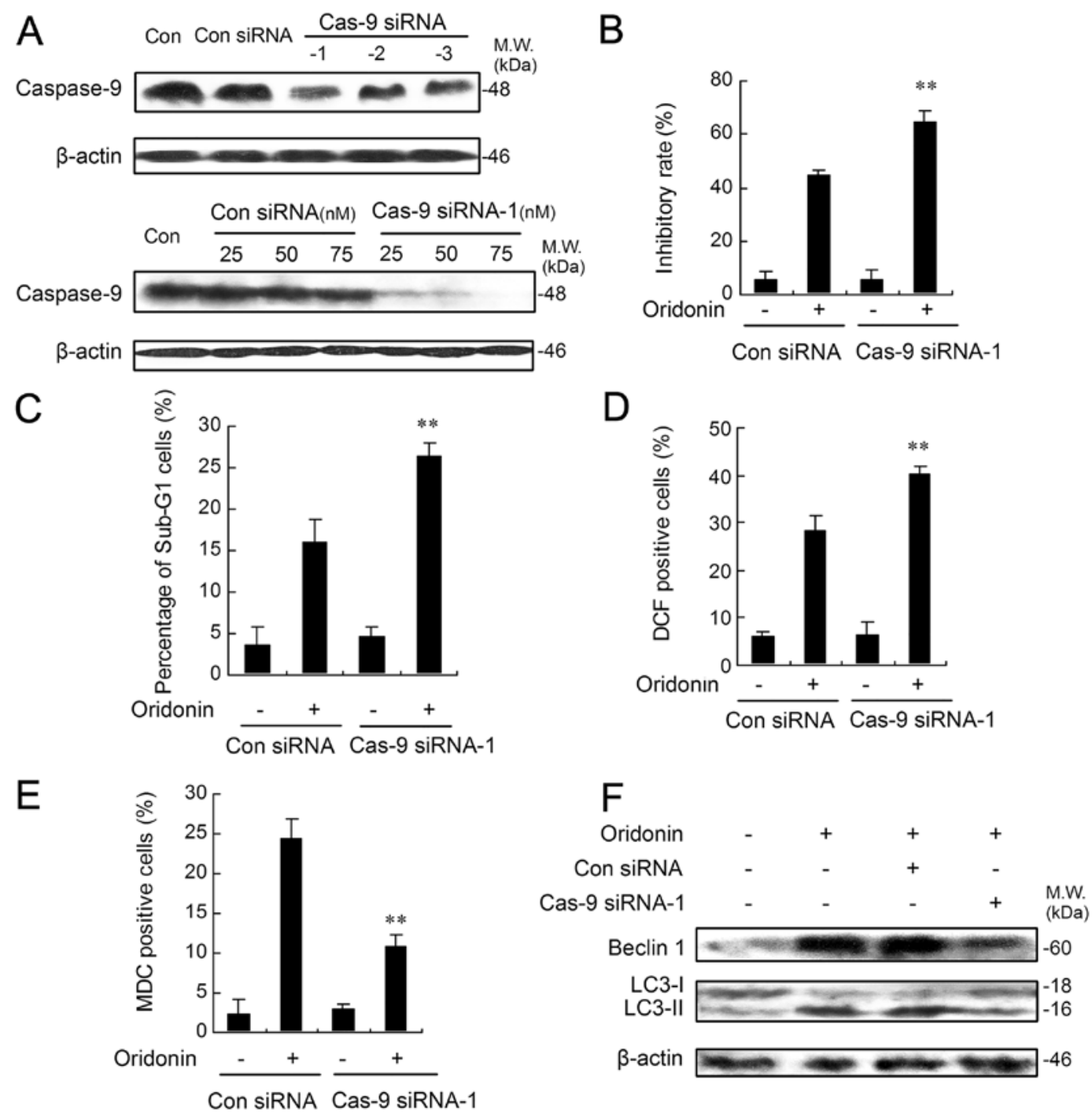

Figure 6. Apoptotic sensitivity to oridonin in HEp-2 cells made deficient in caspase-9 by siRNA. (A) The cells were transfected with $25 \mathrm{nM}$ caspase-9 siRNA-1, $-2,-3$ or control siRNA for $24 \mathrm{~h}$ (upper panel) or transfected with 25-75 nM caspase-9 siRNA-1 or control siRNA for $24 \mathrm{~h}$ (lower panel), and the caspase-9 level was examined by western blot analysis. The cells were transfected with $25 \mathrm{nM}$ caspase-9 siRNA-1 or control siRNA for $24 \mathrm{~h}$, followed by stimulation with oridonin for $24 \mathrm{~h}$. Then, the inhibitory ratio was determined by MTT assay (n=3, mean \pm SD) (B), and the proportion of sub-G1 cells (C) and ROS generation (D) were measured by flow cytometry. The MDC fluorescent intensity of oridonin-treated cells was analyzed by flow cytometry (E), and the Beclin 1 and LC3 levels were examined by western blot analysis $(\mathrm{F})$. The results shown here are representative of at least three independent experiments. ${ }^{* * *} \mathrm{P}<0.01 \mathrm{vs}$ control siRNA group treated with oridonin.

in mitochondria began to decrease at $6 \mathrm{~h}$, which was consistent with the increase in cytochrome $c$ in the cytosol. However, no apparent change was observed in the protein level of pro-caspase-9, and cleaved-caspase-9 could not be detected (Fig. 5A). Recently, several investigators have described negative regulation of the apoptosome complex by Hsp90 $(33,34)$. Therefore, the effect of oridonin on expression of Hsp90 was examined. The result shows that oridonin treatment increased levels of Hsp90 in a time-dependent manner in HEp-2 cells (Fig. 5A).

Next, we directly examined the effect of drug treatments on caspase- 9 activation using functional assays. The result shows that caspase-9 activity was activated in a timedependent manner, and the maximal activity was seen after a 24-h incubation (Fig. 5B). As expected, marked suppression of the high levels of caspase- 9 was noted in cells subjected to combination-treatment with C9i (Fig. 5B).
Lower expression of caspase-9 augments apoptosis in oridonin-treated HEp-2 cells. To determine whether the results obtained with $\mathrm{C} 9 \mathrm{i}$ could be corroborated by another method, we turned to RNA interference using siRNA. Here, the role of caspase- 9 in oridonin-mediated apoptosis was studied by knock-down of caspase- 9 using 3 different specific siRNAs. The expression of capase-9 was markedly suppressed in HEp-2 cells when transfected with caspase-9 siRNA-1 while only slight downregulation was found with the other two siRNAs (Fig. 6A). Therefore, caspase-9 siRNA-1 was selected as a valid candidate for the subsequent investigation. As shown in Fig. 6A, caspase-9 siRNA-1 effectively and specifically suppressed HEp- 2 caspase- 9 protein in a dose-dependent manner. In contrast, an identical amount of control siRNA had no effect on caspase-9. We then tested whether caspase-9-deficient HEp-2 cells would undergo a heightened response to apoptotic stimuli. As shown in 

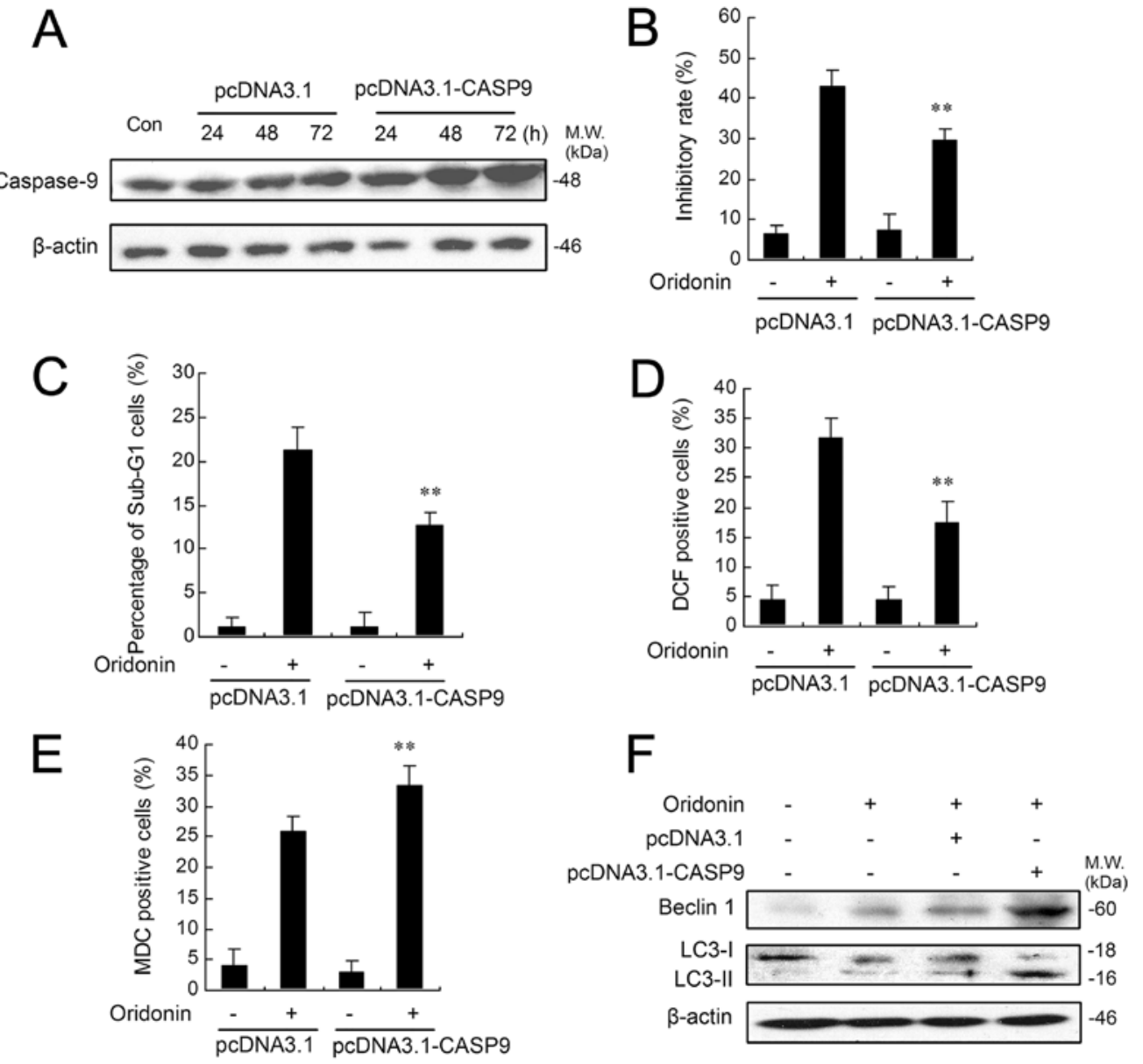

Figure 7. Caspase-9 overexpression attenuates apoptosis in oridonin-treated HEp-2 cells. (A) The cells were transfected with CASP9-expressing plasmid or control plasmid for 24, 48 and $72 \mathrm{~h}$, and the caspase-9 level was examined by western blot analysis. The cells were transfected with CASP9-expressing plasmid or control plasmid for $48 \mathrm{~h}$, followed by stimulation with oridonin for $24 \mathrm{~h}$. Then, the inhibitory ratio was determined by MTT assay ( $\mathrm{n}=3$, mean \pm SD) (B), and the proportion of sub-G1 cells (C) and ROS generation (D) were measured by flow cytometry. The MDC fluorescent intensity of oridonin-treated cells was analyzed by flow cytometry (E), and the Beclin 1 and LC3 levels were examined by western blot analysis (F). The results shown here are representative of at least three independent experiments. ${ }^{* *} \mathrm{P}<0.01$ vs control plasmid group treated with oridonin.

Fig. 6B, caspase-9-deficient HEp-2 cells were significantly more sensitive to oridonin than control siRNA-treated cells. Quantification of apoptotic cells by flow cytometric analysis showed that the incidence of apoptosis after oridonin treatment was increased by $>10 \%$ in caspase- 9 siRNA-1-transfected cells when compared with control siRNA (Fig. 6C). Next, the degree of ROS generation was also determined by flow cytometric analysis. The percentage of DCF-positive cells was highest in caspase-9 siRNA-1-transfected cells treated with oridonin (Fig. 6D). However, caspase-9-deficient HEp-2 cells showed a much reduced autophagic ratio after oridonin treatment when compared with those transfected with control siRNA (Fig. 6E). Accordingly, oridonin treatment, with or without control siRNA, enhanced both the expression level of Beclin 1 and the conversion from LC3-I to LC3-II, while these enhancements were markedly suppressed in HEp-2 cells transfected with caspase-9 siRNA-1 (Fig. 6F).

Caspase-9 overexpression attenuates apoptosis in oridonintreated HEp-2 cells. To test the ability of caspase-9 to inhibit oridonin-induced apoptosis, we transfected HEp-2 cells with a CAS9-expressing plasmid (pcDNA3.1-hCASP9-3FLAG) or control plasmid (pcDNA3.1-3FLAG). After 24, 48 or $72 \mathrm{~h}$ of transfection, the effectiveness of transfection was detected by western blotting. As shown in Fig. 7A, caspase-9 protein level was significantly increased in a time-dependent manner in the HEp-2 cells transiently transfected with the CAS9expressing plasmid. In contrast, the control plasmid had no effect on caspase-9 expression. We then tested whether increased caspase- 9 expression would promote survival and diminish apoptosis in oridonin-treated HEp-2 cells. As shown in Fig. 7B, the inhibitory ratio of control plasmid-transfected cells is $42.80 \%$, while, the inhibitory ratio of CAS9-expressing plasmid-transfected cells is $29.64 \%$, thus demonstrating caspase-9-mediated increase in survival. Moreover, quantification of apoptotic cells by flow cytometric analysis showed that the incidence of apoptosis after oridonin treatment was decreased by nearly $10 \%$ in CAS9-expressing plasmid-transfected cells when compared with control plasmid (Fig. 7C). Next, the degree of ROS generation was also determined by flow cytometric analysis. The percentage of DCF-positive cells was significantly decreased in CAS9-expressing plasmidtransfected cells compared with control plasmid (Fig. 7D). However, CAS9-expressing plasmid-transfected HEp-2 cells showed a much increased autophagic ratio after oridonin treatment when compared with those transfected with control 


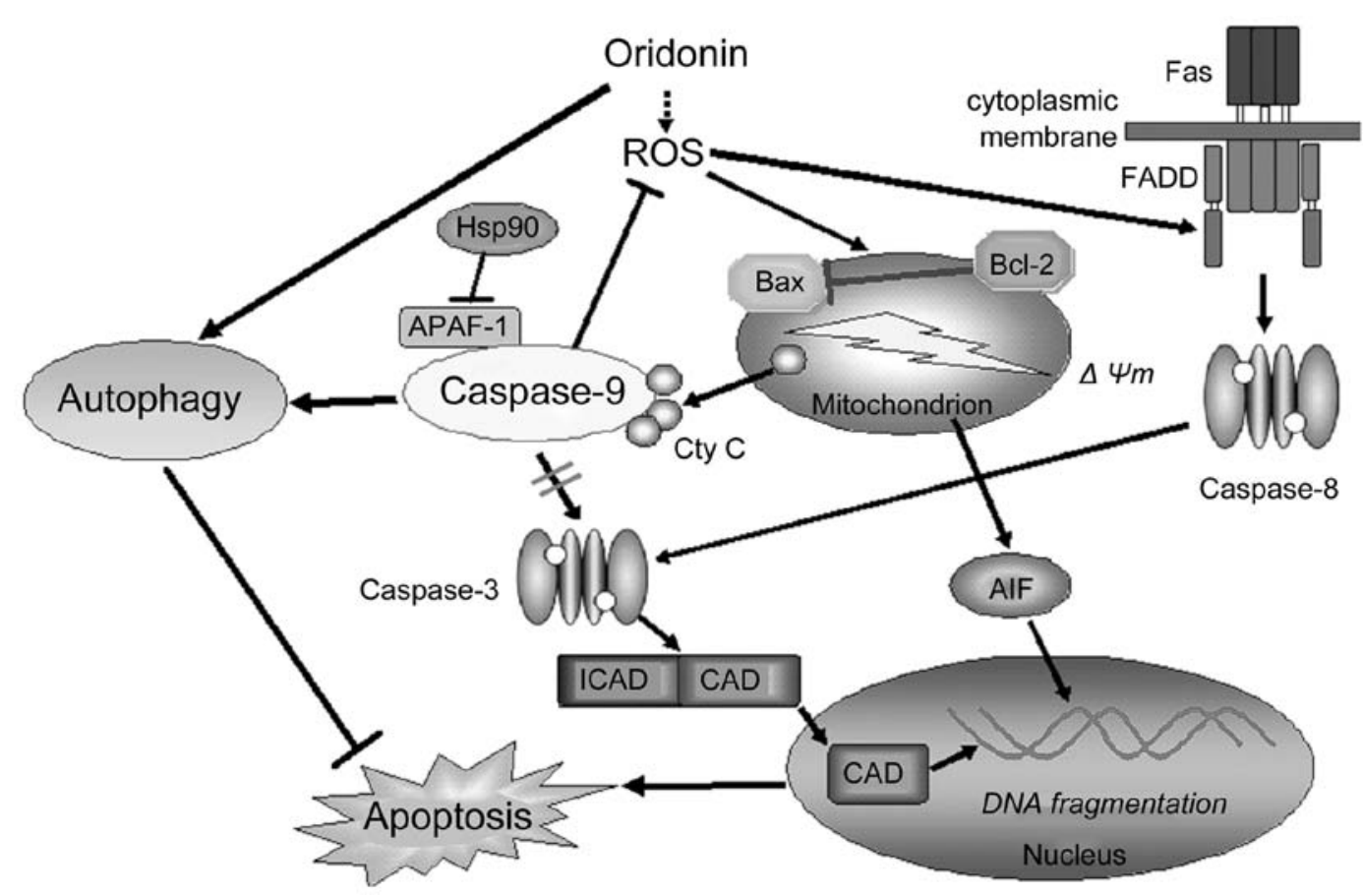

Figure 8. Molecular mechanisms by which caspase-9 resists apoptosis in human laryngeal cancer HEp-2 cells. Caspase-9 reduces sensitivity to apoptosis via ROS-suppressing and autophagy-promoting methods.

plasmid (Fig. 7E). Accordingly, oridonin treatment, with or without control plasmid, enhanced both the expression level of Beclin 1 and the conversion from LC3-I to LC3-II, while these enhancements were markedly augmented in HEp-2 cells transfected with CAS9-expressing plasmid (Fig. 7F).

\section{Discussion}

Some plant-derived agents have been shown to inhibit cell growth and induce apoptosis in numerous cancer cell types (35). Oridonin, an active diterpenoid isolated from $R$. Rubescens, has been found to exert apoptotic effects in human laryngeal cancer HEp-2 cells by our group $(17,20)$. In this study, we made unexpected observations that the $\mathrm{C} 9 \mathrm{i}$ enhanced apoptosis to oridonin stimuli. The C9i effect was dose-dependent and could be detected at concentrations as low as $5 \mu \mathrm{M}$. This study also provides evidence that sensitization to oridonin-mediated apoptosis by $\mathrm{C} 9 \mathrm{i}$ is dependent on the amplification of ROS production induced by oridonin.

ROS, the products of cellular oxidative stress, have been suggested to regulate the process involved in the initiation of apoptotic signaling (26). Several studies have shown that ROS are responsible for the execution of the mitochondrial pathway of apoptosis (36-38). In this study, we observed that oridonin treatment resulted in a significant increase in Bax expression and a decrease in Bcl-2 expression. Our findings also showed a collapse of $\Delta \Psi m$ and a substantial increase in AIF and cytochrome $c$. AIF will translocate to the nucleus where it is capable of inducing nuclear chromatin condensation and large scale DNA fragmentation to mediate a caspase-independent mitochondrial apoptotic pathway (39). Cytochrome $c$ normally functions via its association with other molecules to form a caspase-9-activating complex which plays a key role in the caspase-dependent apoptotic pathway (31). However, in this study, it was interesting to note that cleaved caspase- 9 was not detected by western blot analysis in oridonin-treated cells, although increased expression of cytosolic cytochrome $c$ was observed. Moreover, inhibition of caspase-9 in HEp-2 cells did not protect the cells from oridonin-induced apoptosis, indicating that the apoptosis occurred via a caspase-9-independent mitochondrial pathway. Pre-treatment with NAC and CAT not only reversed the expression of Bax, Bcl-2, AIF and cytochrome $c$, but also resulted in the complete inhibition of oridonin-induced $\Delta \Psi m$ collapse, suggesting that ROS was capable of functioning as an initial mediator in the caspase-9-independent mitochondrial apoptotic pathway.

Fas receptor-mediated apoptotic signaling is one of the most important extrinsic apoptotic pathways in cells (40). ROS generation has been reported to induce the death receptor pathway and increase the activity of caspase- 8 (41). In the present study, the increasing expression of FADD, cleaved caspase- 8 and cleaved caspase- 3 in the oridonin-treated HEp-2 cells suggested the involvement of the death receptor pathway. The activated caspase-3 was further supported by downregulation of ICAD, resulting in the release of CAD which caused DNA fragmentation in the nuclei (29). ROS scavengers NAC and CAT significantly inhibited all the participants in the death receptor pathway in the cells. These results support the notion that ROS plays a primary role in triggering apoptosis through activation of the extrinsic pathway in HEp-2 cells.

Despite the many studies on the relationship between autophagy and apoptosis, the functional relationship between caspases and autophagy is not well understood (42). Recent studies show that caspase- 6 and -8 cleavage of p62 can inhibit autophagy (43). On the other hand, the cleavage of Beclin 1 has been shown to be a critical event whereby caspases inhibit 
autophagy $(44,45)$. Moreover, clinical therapies involving caspase inhibitors may arrest apoptosis but also have the unanticipated effect of promoting autophagic cell death (46). Thus, caspase, the hallmark of apoptosis, may be involved in the execution of autophagy, pointing to major cross-talk between the two lethal subroutines. In the present study, the results indicated that caspase- 9 participated in the autophagy process and acted as a promoting factor in oridonin-induced autophagy. The reason why we were interested in the role of the regulators of apoptosis, such as caspase-9, in oridonin-induced autophagy was that, depending on the circumstances, autophagy can protect cells from apoptosis (47) or kill cells by promoting apoptosis (48). It is known in this regard that autophagy may act as a regulator of oridonin-induced apoptosis in HEp- 2 cells. Here, inhibition of autophagy increased the apoptotic ratio in oridonin-induced HEp-2 cells, suggesting that autophagy has an anti-apoptotic function. Recently, Jeong et al showed that treatment of breast cancer MCF-7 cells with the NSAID FR122047 led to caspase-mediated apoptosis and simultaneously stimulated cytoprotective autophagy (42). In the present study we have also identified a novel caspase-9-dependent mechanism that suppresses oridonin-induced apoptosis of HEp-2 cells by promoting autophagy.

Of note, the release of cytochrome $c$ from mitochondria results in the formation of an Apaf-1-caspase-9 apoptosome and induces the apoptotic protease cascade $(31,32)$. Here, it is interesting to note that the HEp-2 cells treated with oridonin are deficient in their ability to cleave procaspase- 9 in the presence of cytochrome $c$. The regulation and activation of caspase- 9 in the apoptosome complex is poorly understood. Inhibitors of the apoptosome, such as Hsp90, have been described recently $(33,34)$. Hsp90 has been shown to inhibit cytochrome $c$-mediated oligomerization of Apaf-1 and subsequent activation of procaspase-9 (33). In this study, Hsp90 is overexpressed in oridonin-treated HEp-2 cells. It is possible that Hsp90, as an inhibitory factor, interferes with the oligomerization of Apaf-1 to inhibit caspase-9 activation. The detailed mechanisms by which pro-caspase- 9 was not activated by proteolysis in oridonin-treated HEp-2 cells remain to be determined. Next, we focussed on whether the defect in the pro-caspase- 9 cleavage was the equivalent of the absence of caspase-9 enzymatic activity. Therefore, we directly measured the enzyme activity of caspases- 9 by spectrofluorometric assay. The enzyme activity of caspase-9 peaked at $\sim 24 \mathrm{~h}$, while C9i markedly inhibited caspase-9 activity. Obviously, in this study, there must be another mechanism to achieve the catalytically competent form because proteolysis is not required for activation of caspase-9. Other investigators have described the presence of an alternative mechanism in which caspase-9 requires association with specific cofactors, such as Apaf-1, for its activation (49,50). Apaf-1 increases the catalytic activity of caspase- 9 by allosteric regulation (50). The competent form of caspase-9 subsequently reduces sensitivity to apoptotic stimuli through ROS-suppressing and autophagy-promoting methods in our model, which is certainly different from the rule that protease caspase- 9 is the central participant in apoptosis (Fig. 8).

Given the limitations of using a short peptide inhibitor such as C9i, we used RNA interference to more directly assess the role of caspase-9. HEp-2 cells deficient in caspase-9 exhibited enhanced growth inhibitory as well as an apoptotic response to oridonin, consistent with the results obtained with C9i. Moreover, caspase-9-deficient HEp-2 cells also exhibited a significantly enhanced level of ROS and a much reduced autophagic ratio after oridonin treatment. Overall, our findings support the idea that the promotion of ROS, but the repression of autophagy might contribute to the failure to reduce apoptotic sensitivity in caspase-9-deficient HEp-2 cells. By contrast, overexpression of caspase- 9 enhanced autophagy and suppressed ROS production, showing a protective role on oridonin-induced apoptosis in HEp-2 cells.

In conclusion, our data indicate that targeting caspase9-dependent signals can cooperate in promoting cell death induced by anticancer drugs. Thus, the combination of oridonin and those leading to a reduction of caspase-9 in tumor cells with agents, such as $\mathrm{C} 9 \mathrm{i}$ and/or reduction in caspase-9, could represent a novel approach to human laryngeal cancer treatment.

\section{Acknowledgements}

This study was supported by National Natural Science Foundation of China (no. 81102855), China Postdoctoral Science Foundation (no. 2013M541192) and China Postdoctoral Science Special Foundation (no. 2014T70224).

\section{References}

1. Danial NN and Korsmeyer SJ: Cell death: Critical control points. Cell 116: 205-219, 2004

2. Yuan J and Yankner BA: Apoptosis in the nervous system. Nature 407: 802-809, 2000

3. Hanahan D and Weinberg RA: The hallmarks of cancer. Cell 100: 57-70, 2000.

4. Nathan C: Specificity of a third kind: Reactive oxygen and nitrogen intermediates in cell signaling. J Clin Invest 111: 769-778, 2003.

5. Ohsawa I, Ishikawa M, Takahashi K, Watanabe M, Nishimaki K, Yamagata K, Katsura K, Katayama Y, Asoh S and Ohta S: Hydrogen acts as a therapeutic antioxidant by selectively reducing cytotoxic oxygen radicals. Nat Med 13: 688-694, 2007.

6. Pelicano H, Carney D and Huang P: ROS stress in cancer cells and therapeutic implications. Drug Resist Updat 7: 97-110, 2004.

7. Reggiori F and Klionsky DJ: Autophagy in the eukaryotic cell. Eukaryot Cell 1: 11-21,2002.

8. Mathew R, Karantza-Wadsworth V and White E: Role of autophagy in cancer. Nat Rev Cancer 7: 961-967, 2007.

9. Amaravadi RK and Thompson CB: The roles of therapy-induced autophagy and necrosis in cancer treatment. Clin Cancer Res 13: 7271-7279, 2007.

10. Mizushima N, Levine B, Cuervo AM and Klionsky DJ: Autophagy fights disease through cellular self-digestion. Nature 451: 1069-1075, 2008.

11. Marioni G, Marchese-Ragona R, Cartei G, Marchese F and Staffieri A: Current opinion in diagnosis and treatment of laryngeal carcinoma. Cancer Treat Rev 32: 504-515, 2006.

12. Rafferty MA, Fenton JE and Jones AS: The history, aetiology and epidemiology of laryngeal carcinoma. Clin Otolaryngol Allied Sci 26: 442-446, 2001.

13. Wang Z, Wang N, Chen J and Shen J: Emerging glycolysis targeting and drug discovery from Chinese medicine in cancer therapy. Evid Based Complement Alternat Med 2012: 873175, 2012.

14. Yang YC, Wei MC and Huang TC: Optimisation of an ultrasound-assisted extraction followed by RP-HPLC separation for the simultaneous determination of oleanolic acid, ursolic acid and oridonin content in Rabdosia rubescens. Phytochem Anal 23: 627-636, 2012.

15. Fujita T, Takeda Y, Sun HD, Minami Y, Marunaka T, Takeda S, Yamada Y and Togo T: Cytotoxic and antitumor activities of Rabdosia diterpenoids. Planta Med 54: 414-417, 1988. 
16. Huang J, Wu L, Tashiro S, Onodera S and Ikejima T: Reactive oxygen species mediate oridonin-induced HepG2 apoptosis through p53, MAPK, and mitochondrial signaling pathways. J Pharmacol Sci 107: 370-379, 2008.

17. Kang N, Zhang JH, Qiu F, Chen S, Tashiro S, Onodera S and Ikejima T: Induction of $\mathrm{G}(2) / \mathrm{M}$ phase arrest and apoptosis by oridonin in human laryngeal carcinoma cells. J Nat Prod 73: 1058-1063, 2010.

18. Wu JN, Huang J, Yang J, Tashiro S, Onodera S and Ikejima T: Caspase inhibition augmented oridonin-induced cell death in murine fibrosarcoma 1929 by enhancing reactive oxygen species generation. J Pharmacol Sci 108: 32-39, 2008.

19. Shah N, Asch RJ, Lysholm AS and Lebien TW: Enhancement of stress-induced apoptosis in B-lineage cells by caspase- 9 inhibitor. Blood 104: 2873-2878, 2004.

20. Kang N, Zhang JH, Qiu F, Tashiro S, Onodera S and Ikejima T: Inhibition of EGFR signaling augments oridonin-induced apoptosis in human laryngeal cancer cells via enhancing oxidative stress coincident with activation of both the intrinsic and extrinsic apoptotic pathways. Cancer Lett 294: 147-158, 2010.

21. Lu Y, Sun C and Pan Y: Isolation and purification of oridonin from Rabdosia rubescens using upright counter-current chromatography. J Sep Sci 29: 314-318, 2006.

22. Yu C, Wang L, Lv B, Lu Y, Zeng L, Chen Y, Ma D, Shi T and Wang L: TMEM74, a lysosome and autophagosome protein, regulates autophagy. Biochem Biophys Res Commun 369: 622-629, 2008

23. Kim RH, Coates JM, Bowles TL, McNerney GP, Sutcliffe J, Jung JU, Gandour-Edwards R, Chuang FY, Bold RJ and Kung HJ: Arginine deiminase as a novel therapy for prostate cancer induces autophagy and caspase-independent apoptosis. Cancer Res 69: 700-708, 2009.

24. Zhang Y, Wu Y, Cheng Y, Zhao Z, Tashiro S, Onodera S and Ikejima T: Fas-mediated autophagy requires JNK activation in HeLa cells. Biochem Biophys Res Commun 377: 1205-1210, 2008.

25. Wang HJ, Tashiro S, Onodera $\mathrm{S}$ and Ikejima T: Inhibition of insulin-like growth factor 1 receptor signaling enhanced silibinin-induced activation of death receptor and mitochondria apoptotic pathways in human breast cancer MCF-7 cells. J Pharmacol Sci 107: 260-269, 2008.

26. Schumacker PT: Reactive oxygen species in cancer cells: Live by the sword, die by the sword. Cancer Cell 10: 175-176, 2006.

27. Sablina AA, Budanov AV, Ilyinskaya GV, Agapova LS, Kravchenko JE and Chumakov PM: The antioxidant function of the p53 tumor suppressor. Nat Med 11: 1306-1313, 2005.

28. Wong YT, Ruan R and Tay FE: Relationship between levels of oxidative DNA damage, lipid peroxidation and mitochondrial membrane potential in young and old F344 rats. Free Radic Res 40: 393-402, 2006.

29. Sakahira H, Enari M and Nagata S: Functional differences of two forms of the inhibitor of caspase-activated DNase, ICAD-L, and ICAD-S. J Biol Chem 274: 15740-15744, 1999.

30. Trejo-Solís C, Jimenez-Farfan D, Rodriguez-Enriquez S, Fernandez-Valverde F, Cruz-Salgado A, Ruiz-Azuara L and Sotelo J: Copper compound induces autophagy and apoptosis of glioma cells by reactive oxygen species and JNK activation. BMC Cancer 12: 156, 2012.

31. Cain K, Bratton SB, Langlais C, Walker G, Brown DG, Sun XM and Cohen GM: Apaf-1 oligomerizes into biologically active approximately $700-\mathrm{kDa}$ and inactive approximately 1.4-MDa apoptosome complexes. J Biol Chem 275: 6067-6070, 2000.

32. Hu Y, Benedict MA, Ding L and Núñez G: Role of cytochrome $c$ and dATP/ATP hydrolysis in Apaf-1-mediated caspase-9 activation and apoptosis. EMBO J 18: 3586-3595, 1999.

33. Pandey P, Saleh A, Nakazawa A, Kumar S, Srinivasula SM, Kumar V, Weichselbaum R, Nalin C, Alnemri ES, Kufe D, et al: Negative regulation of cytochrome $c$-mediated oligomerization of Apaf-1 and activation of procaspase-9 by heat shock protein 90. EMBO J 19: 4310-4322, 2000.
34. Liu JR, Opipari AW, Tan L, Jiang Y, Zhang Y, Tang H and Nuñez G: Dysfunctional apoptosome activation in ovarian cancer: Implications for chemoresistance. Cancer Res 62: 924-931, 2002.

35. Lee KH: Anticancer drug design based on plant-derived natural products. J Biomed Sci 6: 236-250, 1999.

36. Herrera B, Alvarez AM, Sánchez A, Fernández M, Roncero C, Benito $\mathrm{M}$ and Fabregat I: Reactive oxygen species (ROS) mediates the mitochondrial-dependent apoptosis induced by transforming growth factor (beta) in fetal hepatocytes. FASEB J 15: 741-751, 2001.

37. Herrera B, Fernández M, Alvarez AM, Roncero C, Benito M, Gil $\mathbf{J}$ and Fabregat I: Activation of caspases occurs downstream from radical oxygen species production, Bcl-xL down-regulation, and early cytochrome $\mathrm{C}$ release in apoptosis induced by transforming growth factor beta in rat fetal hepatocytes. Hepatology 34: 548-556, 2001

38. Chen Q, Chai YC, Mazumder S, Jiang C, Macklis RM, Chisolm GM and Almasan A: The late increase in intracellular free radical oxygen species during apoptosis is associated with cytochrome $c$ release, caspase activation, and mitochondrial dysfunction. Cell Death Differ 10: 323-334, 2003.

39. Daugas E, Nochy D, Ravagnan L, Loeffler M, Susin SA, Zamzami N and Kroemer G: Apoptosis-inducing factor (AIF): A ubiquitous mitochondrial oxidoreductase involved in apoptosis. FEBS Lett 476: 118-123, 2000.

40. Mitsiades CS, Poulaki V, Fanourakis G, Sozopoulos E, McMillin D, Wen Z, Voutsinas G, Tseleni-Balafouta S and Mitsiades N: Fas signaling in thyroid carcinomas is diverted from apoptosis to proliferation. Clin Cancer Res 12: 3705-3712, 2006.

41. Chandra J, Samali A and Orrenius S: Triggering and modulation of apoptosis by oxidative stress. Free Radic Biol Med 29: 323-333, 2000.

42. Jeong HS, Choi HY, Lee ER, Kim JH, Jeon K, Lee HJ and Cho SG: Involvement of caspase-9 in autophagy-mediated cell survival pathway. Biochim Biophys Acta 1813: 80-90, 2011.

43. Norman JM, Cohen GM and Bampton ET: The in vitro cleavage of the hAtg proteins by cell death proteases. Autophagy 6: 1042-1056, 2010.

44. Young MM, Takahashi Y, Khan O, Park S, Hori T, Yun J, Sharma AK, Amin S, Hu CD, Zhang J, et al: Autophagosomal membrane serves as platform for intracellular death-inducing signaling complex (iDISC)-mediated caspase- 8 activation and apoptosis. J Biol Chem 287: 12455-12468, 2012.

45. Cho DH, Jo YK, Hwang JJ, Lee YM, Roh SA and Kim JC: Caspase-mediated cleavage of ATG6/Beclin-1 links apoptosis to autophagy in HeLa cells. Cancer Lett 274: 95-100, 2009.

46. Wang ZH, Xu L, Duan ZL, Zeng LQ, Yan NH and Peng ZL: Beclin 1-mediated macroautophagy involves regulation of caspase-9 expression in cervical cancer HeLa cells. Gynecol Oncol 107: 107-113, 2007.

47. Lum JJ, Bauer DE, Kong M, Harris MH, Li C, Lindsten T and Thompson CB: Growth factor regulation of autophagy and cell survival in the absence of apoptosis. Cell 120: 237-248, 2005

48. Crighton D, Wilkinson S, O'Prey J, Syed N, Smith P, Harrison PR, Gasco M, Garrone O, Crook T and Ryan KM: DRAM, a p53-induced modulator of autophagy, is critical for apoptosis. Cell 126: 121-134, 2006

49. Rodriguez J and Lazebnik Y: Caspase-9 and APAF-1 form an active holoenzyme. Genes Dev 13: 3179-3184, 1999.

50. Stennicke HR, Deveraux QL, Humke EW, Reed JC, Dixit VM and Salvesen GS: Caspase-9 can be activated without proteolytic processing. J Biol Chem 274: 8359-8362, 1999. 